\title{
Sustainability of Information Technology in Higher Education Institutions: New Concept
}

\author{
Syahril $^{\mathrm{a}, 1}$, Yulherniwati ${ }^{\mathrm{b}, 2}$ \\ ${ }^{\mathrm{a}}$ Faculty of Engineering, Padang State University, Padang, INDONESIA \\ ${ }^{\mathrm{b}}$ Department of Information Technology, Padang State Polytechnic, Padang, INDONESIA \\ ${ }^{1}$ sy_ril@yahoo.com, ${ }^{2}$ heni32@yahoo.com
}

\begin{abstract}
The new paradigm of higher education requires higher education institutions (HEIs) to be managed by utilizing information technology (IT). This has been recognized by the HEIs, but it did not go smoothly. Frequently occur in development process, the re-creation of the necessary facilities (low sustainability). This article discusses the cause identification of low IT sustainability in HEIs and proposes solution that is Service Oriented Architecture (SOA) concept. The identification process is done by means of literatures review and observation followed by process of analysis utilizing root cause analysis and worst case analysis, with fishbone diagrams and checklist as instruments. It concluded that the root cause of low IT sustainability is the approach or development method that cannot adapt to changes and does not consider collaborations. The exploiting of SOA concept is suitable to solve the problem based on the worst case analysis. Thus, IT-based systems in HEIs will be sustain.
\end{abstract}

Index Terms - sustainability; information technology; higher education institutions; service oriented architecture (SOA)

\section{Introduction}

Higher Education Institutions (HEIs) are obliged to provide education, research, and community service. The new paradigm of higher education rests on the quality and relevance. The quality and relevance are supported by four interrelated pillars, namely autonomy, accreditation, accountability and evaluation. With the accreditation and accountability, HEIs are required to be accountable to the public. As a counterpart, the HEIs are given the authority and flexibility to manage and develop themself with autonomy. The evaluation mechanism is used as a control tool for the implementation to stay in the right direction [16].

The new paradigm requires HEIs to be managed by utilizing information technology (IT). IT can be an enabler for various efforts to enhance quality, effectiveness, efficiency and accountability of HEIs [1]. In a broad definition, IT describes an organization's collection of information systems, their users, and the management that oversees them [2]. Some of the objectives of IT in higher education according to [3] are: (a) improving competitive positioning; (b) improving brand image; (c) improving quality of learning and teaching; (d) increasing student satisfaction; (e) increasing revenues; (f) expanding student base; (g) improving quality of service; (h) reducing operating costs; and (i) developing new products and services. According to [4], HEIs in Indonesia has nine major information systems, namely (a) new student admission information systems, (b) academic information system, (c) e-learning systems, (d) library information system, (e) laboratory information system, (f) curriculum information systems, (g) research and community service information systems, (h) alumni and career information systems, and (i) academic reporting information system (EPSBED). These applications should be available in every HEI in Indonesia, so that HEI's business processes are not interrupted or get obstacles.

In addition to its important role, there are also problems in IT implementation. In many organizations, occurs several times changes of IT or information systems. The same thing happened in HEIs. Equipment and skills have a short life cycle [5]. As a result, a lot of time, effort and money spent in activities of system development, installation, data migration and training. Then, the system is used, but after some time, the system is not used anymore because the software becomes obsolete [6], is considered as no longer able to meet the needs. Based on these facts, it is concluded that there is low IT sustainability problem in HEIs. This can hamper the sustainability and continuous improvement processes in all aspects of HEI's management. IT sustainability is often associated with "green-IT" which includes the economic, social and environmental dimension. However, in this article the definition of IT sustainability used is based on the opinion of [7], and [8]. IT sustainability refers to the technology that can be maintained over a long span of time, independent of shifts in hardware and software [7].

This article begins with cause identification of low IT sustainability in HEIs. The data collection methods used are literatures review and observation. After the causes of the problem are identified, then the needs for a new concept are identified. Based on these needs, a new concept is proposed and its application is analyzed in worst cases as a solution to overcome the problem. The purposes of this article are: a) to identify the causes of low IT sustainability in HEIs; b) to propose new concept to solve the IT sustainability problem in HEIs.

\section{Methods}

The steps performed are as follows: a) literatures review of IT sustainability; b) observation of low IT sustainability causes in higher education instituions using internet sources; c) root cause analysis of low IT sustainability based on literatures review and observation; d) needs identification and new concept selection to solve the low IT sustainability problem; e) worst case analysis of IT sustainability with the application of the selected new concept. The instruments used are: a) fishbone diagram as a tool to describe causes of low IT sustainability problem; and b) checklist as a tool in 
examining whether the proposed concept has relevant capabilities to solve low sustainability IT problem.

\section{Results and Discussion}

This section contains three main discussions, which are: a) root cause analysis; b) needs identification and new concept selection; c) worst case analysis with application of the new concept proposed; regarding low IT sustainability problem in HEIs.

\section{A. Root Cause of Low IT Sustainability}

Based on IT sustainability definitions and the results of observation, IT issues in HEIs related to IT sustainability are found in several publications, as in [5], [6], [9], [10], [11], [12], [13], [14], [15], [16], [17], [18]. According to those IT issues related to low IT Sustainability in HEIs, the problem causes are identified and described in fishbone diagram. They are classified in several factor categories, namely Data, Human Resources, Technology, Organization, and Stakeholders; as shown in Fig.1. Then the root cause of low IT sustainability in HEIs is analyzed, as shown in Fig. 2. In root cause analysis, a number of questions "why" is given over and over regarding the possible causes, so that the root causes of the problem are identified. From the analysis it is concluded that the root cause of the problem is the approach or system development method which (a) is not adaptive to changes and (b) does not consider the inter-system collaborations.

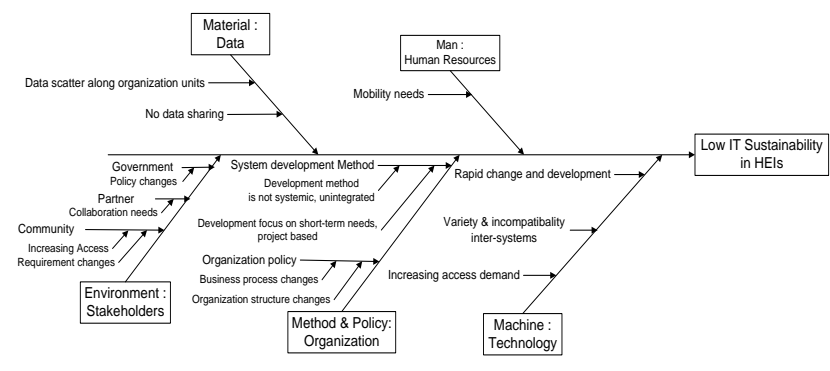

Fig. 1. Fishbone Diagram of Low IT Sustainability in HEIs

\section{B. Needs Identification and New Concept Selection}

Referring to the root cause and base on the causes of low IT sustainability in Fishbone Diagram, a checklist is generated. The checklist, as shown in Table I, describes what capabilities are needed for the new concept.

Approach or system development method is identified as the root cause of low IT sustainability problem in HEIs, which is not adaptive to changes and does not consider collaborations. There are number of concept related to the way of developing IT system, namely Structured Analysis and Design in monolithic architecture, Object-Oriented Modelling in Layered Architecture, Component Based Development in Component Architecture, and Service Oriented Modeling in Service Oriented Architecture (SOA). Structured Analysis and Design use traditional method, that follows a sequential phase wise manner where all the requirements are gathered at the beginning. It limits the system requirement to be changed in the middle of development. Agile method is introduced to overcome the deficiencies of traditional method. Agile method can be applied to Object Oriented Modelling, Component Based Development and Service Oriented Modelling. This method embraces iterations, adopts the incremental and iterative approach to improve the productivity and efficiency of the development process. So that, compare to traditional methods, they're relatively easy to change [17]. The first three method is platform spesific, but SOA allows the system built to be platform independent. Therefore, for its agility and interoperability, SOA is selected as the new concept to solve the low IT sustainability problem in HEIs.

\begin{tabular}{|c|c|c|c|c|c|}
\hline \multicolumn{6}{|c|}{ Why is IT sustainability in HEls low? } \\
\hline $\begin{array}{l}\text { a1 } \\
\text { Technology } \\
\text { adaptation is } \\
\text { inefficient. }\end{array}$ & $\begin{array}{l}\text { b1 } \\
\text { Frequent } \\
\text { rebuild of the } \\
\text { system. }\end{array}$ & $\begin{array}{c}c 1 \\
\text { Rebuild the } \\
\text { system to get } \\
\text { the more } \\
\text { integrated } \\
\text { system }\end{array}$ & \multicolumn{2}{|c|}{$\begin{array}{l}\text { d1 } \\
\text { Build new system to serve } \\
\text { information exchange with } \\
\text { other organizations }\end{array}$} & $\begin{array}{c}\text { e1 } \\
\text { Process } \\
\text { redundancies } \\
\text { among } \\
\text { organization } \\
\text { units. }\end{array}$ \\
\hline a2 & b2 & $\mathrm{c} 2$ & \multirow{2}{*}{\multicolumn{2}{|c|}{$\begin{array}{l}\text { d2 } \\
\text { In today's system it is not } \\
\text { possible to exchange } \\
\text { information easily with other } \\
\text { organizations }\end{array}$}} & $\mathrm{e} 2$ \\
\hline $\begin{array}{l}\text { Technology } \\
\text { adaptation } \\
\text { cost is high }\end{array}$ & $\begin{array}{c}\text { Today's } \\
\text { system is } \\
\text { discontinue } \\
\text { (not } \\
\text { operated) } \\
\text { anymore) }\end{array}$ & $\begin{array}{l}\text { In today's } \\
\text { system it is } \\
\text { not possible to } \\
\text { exchange } \\
\text { information } \\
\text { easily } \\
\text { between } \\
\text { organization } \\
\text { units. }\end{array}$ & & & $\begin{array}{l}\text { System is } \\
\text { built based on } \\
\text { projects. }\end{array}$ \\
\hline $\begin{array}{c}\text { a3 } \\
\text { Frequent } \\
\text { changes in } \\
\text { hardware, } \\
\text { software, } \\
\text { installation. }\end{array}$ & $\begin{array}{c}\text { b3 } \\
\text { Today's } \\
\text { system does } \\
\text { not meet the } \\
\text { requirements } \\
\text { /needs } \\
\text { anymore. }\end{array}$ & $\begin{array}{c}\text { c3 } \\
\text { Today's } \\
\text { system can } \\
\text { not share data } \\
\text { with other } \\
\text { systems. }\end{array}$ & $\begin{array}{l}\text { d3.a } \\
\text { Today's } \\
\text { system can } \\
\text { not share } \\
\text { data with } \\
\text { other } \\
\text { systems. } \\
\end{array}$ & $\begin{array}{l}\text { d3.b } \\
\text { Diversity and } \\
\text { incompatibility } \\
\text { technologies. }\end{array}$ & $\begin{array}{c}\text { e3 } \\
\text { System is } \\
\text { built to meet } \\
\text { short term } \\
\text { needs. }\end{array}$ \\
\hline $\begin{array}{c}\text { a4 } \\
\text { Technology } \\
\text { changes are } \\
\text { difficult to } \\
\text { adapt }\end{array}$ & $\begin{array}{c}\text { b4 } \\
\text { Today's } \\
\text { systems is } \\
\text { difficult to } \\
\text { accomodate } \\
\text { requirement } \\
\text { changes }\end{array}$ & $\begin{array}{c}\text { c4 } \\
\text { Today's } \\
\text { systems } \\
\text { operate } \\
\text { individually }\end{array}$ & $\begin{array}{c}\text { d4.a } \\
\text { Today's } \\
\text { systems in } \\
\text { each } \\
\text { organization } \\
\text { operate } \\
\text { individually. }\end{array}$ & $\begin{array}{l}\mathrm{d} 4 . \mathrm{b} \\
\text { System is } \\
\text { built } \\
\text { separately. }\end{array}$ & $\begin{array}{l}\text { e4 } \\
\text { System } \\
\text { development } \\
\text { method is not } \\
\text { systemic }\end{array}$ \\
\hline $\begin{array}{c}\text { a5 } \\
\text { System } \\
\text { development } \\
\text { method is not } \\
\text { adaptive to } \\
\text { changes }\end{array}$ & $\begin{array}{c}\text { b5 } \\
\text { System } \\
\text { development } \\
\text { method is not } \\
\text { adaptive to } \\
\text { changes }\end{array}$ & $\begin{array}{c}\text { c5 } \\
\text { System } \\
\text { development } \\
\text { method does } \\
\text { not considers } \\
\text { collaborations }\end{array}$ & $\begin{array}{l}\text { d5.a } \\
\text { System } \\
\text { development } \\
\text { method does } \\
\text { not considers } \\
\text { collaborations }\end{array}$ & $\begin{array}{l}\text { d5.b } \\
\text { System } \\
\text { development } \\
\text { method does } \\
\text { not considers } \\
\text { collaborations }\end{array}$ & \begin{tabular}{|c}
\multicolumn{1}{c}{ e5 } \\
System \\
development \\
method does \\
not considers \\
collaborations
\end{tabular} \\
\hline
\end{tabular}

Fig. 2. Root Cause Analysis of Low IT Sustainability in HEIs

TABLE I. CHECKLIST FOR CAPABILITIES NEEDED

\begin{tabular}{ll}
\hline No & \multicolumn{1}{c}{ Question } \\
\hline 1 & Is the system built able to adapt to the IT changes development? \\
2 & $\begin{array}{l}\text { Is the system built able to communicate with other systems that have } \\
\text { different technologies? }\end{array}$ \\
3 & $\begin{array}{l}\text { Is the system built able to respond to increasing technology access } \\
\text { demand? }\end{array}$ \\
4 & Is the system development method allowing systemic development? \\
5 & Is the system built able to meet the long-term needs? \\
6 & Is the system built able to respond to changes in organizational \\
7 & structure? \\
8 & Is the system able built to adopt changes in business processes? \\
9 & Is the system able to quickly respond to changes in policy? \\
10 & Is the system able to cope with increasing public access? \\
11 & Is the system able to adapt to changing needs? \\
12 & Is the system able to access data scattered in different locations? \\
13 & Is the system able to exchange information with other systems? \\
14 & Is the system able to accommodate the mobility of human resources?
\end{tabular}

\section{Worst Case Analysis with SOA}

Here are some worst cases related to IT sustainability in HEIs. Case 1: Finding information quickly is difficult for academic department or faculty regarding teaching loads and schedules of lectures who teach courses across different course programs, or regarding lecture rooms that are shared between course programs. These difficulties occur because academic department, faculties and course programs, each having its own system and having different data formats. 
Case 2: There are needs to speed up and simplify the process of registration and tuition payment, through the cooperation mechanism with banks. It allows the payment status automatically be updated after students pay tuition at bank. By this way, students can directly continue to online registeration for courses and classes without returning to the campus with the payment slips.

Case 3: Emergence of a new government policy that changes the academic activity reporting mechanism, from using application -called EPSBED- to the use of Higher Education Data Center system -called PDPT. Previously, academic system has been developed to be automatically generates EPSBED reports. Because it is not possible to change certain parts of the system, so the alternative taken is rebuilding system which can generate reports for PDPT formats.

Case 4: Frequent changes of information system cause high consuming of employee's productive time in the process of developing, preparing and learning system. Each time a new system is introduced, operator must re-learn how to do his job by utilizing the new system interface. IT staff helps migrating existing data from today's system to new system. For a much different data formats, data migration is not possible to do so that re-entry is conducted.

Case 5: There are new requirements for the today's academic system to have facilities that allows advisor to advise students who are conducting job training or final project from outside the campus. Advisor themselves should also be able to access the system from outside the campus via mobile devices. Today's system did not provide these features and can only be accessed from inside the campus.

Case 6: System requirements change in the coding phase, then the developer re-do the analysis and design phase. The analysis results showed that most of the system modules needs to be changed, so the system is rebuild.

TABLE II. MAPPING OF WORST CASES AND NEW CONCEPT'S CAPABILITIES

\begin{tabular}{lllllllllllllll}
\hline $\begin{array}{l}\text { Worst } \\
\text { Case }\end{array}$ & \multicolumn{11}{c}{ Relevant capabilities to solve the case (referring to Table I) } \\
\hline & 1 & 2 & 3 & 4 & 5 & 6 & 7 & 8 & 9 & 10 & 11 & 12 & 13 & 14 \\
\hline Case 1 & & $\sqrt{ }$ & & $\sqrt{ }$ & $\sqrt{ }$ & & & & $\sqrt{ }$ & & $\sqrt{ }$ & $\sqrt{ }$ & $\sqrt{ }$ & \\
Case 2 & & $\sqrt{ }$ & & $\sqrt{ }$ & $\sqrt{ }$ & & $\sqrt{ }$ & & $\sqrt{ }$ & $\sqrt{ }$ & $\sqrt{ }$ & $\sqrt{ }$ & $\sqrt{ }$ & \\
Case 3 & & & & & & & & $\sqrt{ }$ & & & $\sqrt{ }$ & $\sqrt{ }$ & & \\
Case 4 & & & & $\sqrt{ }$ & $\sqrt{ }$ & & & $\sqrt{ }$ & & & $\sqrt{ }$ & & & \\
Case 5 & $\sqrt{ }$ & $\sqrt{ }$ & $\sqrt{ }$ & $\sqrt{ }$ & & & $\sqrt{ }$ & $\sqrt{ }$ & & $\sqrt{ }$ & $\sqrt{ }$ & & $\sqrt{ }$ & $\sqrt{ }$ \\
Case 6 & & & & & & & & & & & $\sqrt{ }$ & & & \\
\hline
\end{tabular}

Resolving cases related to low IT sustainability problem in HEIs requires new concept which has the capabilities that are relevant to solve the problems. Table II describe a mapping of the worst cases and capabilities of new concepts that are relevant to solve it.

The following section explains the concept of Service Oriented Architecture (SOA) as the proposed solution. The basic idea of SOA is to reuse existing IT assets, namely services, without having to spend time and money to build a new system [2]. According to [20], SOA is a way to design, implement, and assemble service to support or automate business functions. Services are linked, repeatable business tasks [20]. Services are code-running on an underlying computer system - that provide computing as well as access and updates to stored data [21]. There are two types of services, namely atomic and composite. An atomic service is a well-defined, self-contained function that does not depend on the context or state of other services. A composite service is an assembly of atomic or other composite services. A service within a composite service may depend on the context or state of another service that is also within the same composite service [21].

SOA is built using a collection of services that communicate with each other via messages. One of the communication technologies to connect these services is Web Services. Applications that use Web services interact with each other by using a document formatted Extensible Markup Language (XML), a messaging protocol called Simple Object Access Protocol (SOAP), through a communication protocol called Hypertext Transfer Protocol (HTTP). The format of XML, SOAP, and HTTP is an open standard. To be able to find and to communicate, the services must be described. Web Service Description Language (WSDL) is an open standard language for describing services. As for the search mechanism used Universal Description Discovery and Integration (UDDI). UDDI is analogous as Web Service catalogue on the Internet, thus allowing a Web Service application find other applications required [21].

Services are critical to SOA. The process of identifying and designing the right services based on the service orientation principles becomes important in SOA. To obtain services, it should start with identifying business processes, business transactions and then finally identifying services needed. The right service allows organizations to quickly assemble or modify the assembly to services to add or modify support or automation of business functions. The main service principle is "loosely coupled", referring to minimum amount of interdependencies between services. This principle leads to the next principle, that is the ability to be reused ("reusability"). The next principle is "composability". A service can be assembled from other services to form a composite service. SOA abstracting business services from the specific technologies they were originally developed with and the platforms they were meant to run on. It makes services can communicate with each other, although each application written in a different programming language or accessed using different transfer protocols, usually known as interoperability. This principle also supported by other principle, that is "open standard". SOA uses open standards so that any software developers have the right to use the standard when developing SOA products. SOA uses a flexible approach in integration. Unlike previous approaches that use a connection point-topoint or hub-centralized, SOA integrating services through an Enterprise Service Bus (ESB) [21]. With SOA integration techniques, applications with different technologies are loosely-coupled, do not communicate directly, but by using services through the ESB.

The next discussion is the result of the worst-case analysis related to low IT sustainability in HEIs by referring to Table 3. The purpose is to determine whether the concept of SOA has the relevant capabilities to solve the problem has shown in worst cases. SOA for Case 1: For functions that require collaborations between organization units in HEIs, services should be created to access information in each unit without disrupting existing processes in the units. 
This service can be a new composite service of the existing services. Services can communicate and exchange messages using the open standard format that is not limited by the existing differences in data format. The main SOA principles that are supporting are reusability, looselycoupled, composability, interoperability, open standards. It can be concluded in this case that SOA has relevant capabilities of number 2, 4, 5, 9, 10, 11, 12, 13.

SOA for Case 2: In this case there are needs to change business processes. In modifying business processes, the equivalent business service can be recomposed to adapt to the changes. Collaboration with organization outside the higher education institutions can be seen as Business 2 Business (B2B) integration. Provided services can be shared and be reused, without disturbing the process of each organization. With the use of open standards each organization can communicate and share data with each other, although each system uses different technology platforms. The main SOA principles that are supporting are reusability, loosely-coupled, composability, interoperability, open standards. It can be concluded in this case that SOA has relevant capabilities of number $2,4,5,7,9,11,12,13$.

SOA for Case 3: With SOA approach that deviding large task into smaller specific services, adapting changes to systems is easier to do. Changes encountered can be adapted by creating new composite services that are equivalent, to accommodate the changes. The main SOA principles that are supporting are reusability, loosely-coupled, composability. It can be concluded in this case that SOA has relevant capabilities of number $8,11,12$.

SOA for Case 4: With the adoption of SOA, the changing needs and technology do not cause the today's systems to be abandoned and replaced with new systems. Systems can have services updated or new equivalent services to adopt changing needs. By abstracting services from the specific technologies they were originally developed with and the platforms they were meant to run on, HEIs can modify the technology architecture without mandating changes to the services available. Employees can still use the same systems, with updates. Therefore, the high consuming of employees's productive time in developing, preparing and learning new system can be reduced. The main SOA principles that are supporting are reusability and loosely-coupled. It can be concluded in this case that SOA has relevant capabilities of number $4,5,8,11$.

SOA for Case 5: This requirement can be facilitated by SOA, by providing services to implement new business processes regarding online advisory. New services can also be provided for adopting mobile technologies that can share data with today's systems. The service can be an assembly of existing services. The main SOA principles that are supporting are reusability, loosely- coupled, interoperability, open standards. It can be concluded in this case that SOA has relevant capabilities of number $1,2,3,4,7,8,10,11$, 13,14 .

SOA for Case 6: In service-orientation, development of the system is done incrementally. Systems under development or systems have been completed can be adapted to the changes that occur, by identifying services to be changed and then replaced them with new ones. Development can be done through an iterative process. The main SOA principles that are supporting are reusability, loosely-coupled, composability. It can be concluded in this case that SOA has relevant capabilities of number 11.

Based on the worst case analysis, SOA considered as having the capabilities to solve the low IT sustainability problem in HEIs.

\section{Conclusion}

It has shown that the identified main cause of the low IT sustainability in higher education institutions were the approach or system development method which is not adaptive to changes and does not consider inter-system collaborations. Based on the worst case analysis, it concluded that the problem of low IT sustainability in HEIs can be solved by SOA concept.

Therefore, we recommend that future research in IT sustainability in HEIs with SOA should focus on how to support the quality management in HEIs, to achieve continous improvement. It can also consider the adoption of trending technologies in HEIs such as cloud computing.

\section{References}

[1] Directorate General of Higher Education, Ministry of National Education, Republic of Indonesia, Framework for Long-Term Development of Higher Education (2003-2010). Trans. Indonesian, 2003.

[2] Turban, L. Volonino and G. R. Wood, Information Technology for Management: Advancing Sustainable, Profitable Business Growth. Wiley, 2013.

[3] Wahid, "Opportunities and challenges of the use of information technology in higher education". Trans. Indonesian. Media Informatika, Vol. 2, No. 1, June 2004, pp. 11-22, ISSN: 0854-4743, 2004

[4] Solichin, and A. Z. Hasibuan, "Information technology architectural modeling cloud computing based for higher education institutions in indonesia". Trans. Indonesian. Prosiding Seminar Nasional Teknologi Informasi \& Komunikasi Terapan 2012 (Semantik 2012). ISBN 979 26 - 0255 - 0. pp 10-16, 2012.

[5] G.Misund, and J. Hoiberg," "Sustainable Information Technology for Global Sustainability, Digital Earth, Information Resources for Global Sustainability". Symposium, Brno, Czech Republic, pp. 21.-25.9, 2003.

[6] C. Kimaroa, and J. L. Nhampossab, "The challenges of sustainability of health information systems in developing countries: comparative case studies of Mozambique and Tanzania". Journal of Health Informatics in Developing Countries Vol.1 No.1 December 2007.

[7] Z. A. Shaikh, "Usage, Acceptance, Adoption, and Diffusion of Information \& Communication Technologies in Higher Education: A Measurement of Critical Factors". Journal of Information Technology Impact Vol. 9, No. 2, pp. 63-80, 2009.

[8] E. F. Gaviria, Technology Enhanced support for lifelong competence development in higher education, $\mathrm{PhD}$ Thesis, Universitat de Girona. Girona: Spain, 2012, Unpublished.

[9] Surendro, and Aradea, "Information Technology Services Strategy Design for Higher Education Institutions". Trans. Indonesian. Prosiding SNATI 2011, pp F118-F123, 2011.

[10] P. Gonçalves, and M. C. Sapateiro, "Aspects for Information Systems Implementation: Challenges and impacts. A higher education institution experience". Revista de Estudos Politécnicos. Polytechnical Studies Review 2008, Vol VI, no. 9. ISSN: 1645-9911, 2008.

[11] Susan. Grajek, Top-Ten IT Issues, Be the Change You See. EDUCAUSE Review: Print Edition, Volume 49, Number 2, March/April 2014, 2014.

[12] Tho, Meiliana, and Rosmina, "Modeling Information System Standards in Higher Education in Indonesia". Trans. Indonesian. Prosiding SNST ke-4, pp. 21-25, 2013.

[13] Zhou, L. Qin, P. Xie, Z. Zhang, and H. Tao, "SOA-based education information system interoperability model". Journal of Information \& Computational Science 7: 5 (2010), pp: 1165-1174, 2010.

[14] Pandey, and V. M. Thakare, V, M, "SOA enabled e-administration for institutes providing higher education". International Journal Of 
Engineering And Computer, Volume 3 Issue 1 Jan, 2014, pp. 37523757, 2014.

[15] H. Selamat, and A. Al Kharusi, "Service oriented architecture in education sector". IJCSNS International Journal of Computer Science and Network Security, VOL.9 No.5, May 2009, pp. 301-308, 2009.

[16] Kapojos, H. F. Wowor, A. M. Rumagit, and A. P. R. Wowor, "Implementation of service-oriented architecture with web services for academic information applications". Trans. Indonesian. Jurnal Teknik Elektro dan Komputer, Vol 1, No 1, pp. 1-5, 2012.

[17] G. K. Sagitova, "Management information system for higher educational institutions during kazakhstan transition to knowledge economy". World Applied Sciences Journal 18 (Special Issue of Economics), pp.55-60. ISSN 1818-4952, 2012.

[18] C. Lin, K. E. T. Desmond, N. T. Htoon, and N. V. Thuat, A Fresh Graduate's Guide to Software Development Tools and Technologies. Chapter 10 Service Oriented Architecture, National University of Singapore, 2012.

[19] Barry and D. Dick, (2nd ed.), Web Services, Service-Oriented Architectures, and Cloud Computing The Savvy Manager's Guide. Morgan Kaufmann, 2013. 